\title{
I-MARGENS DE UM CARUANA ENTRE ESTÉTICAS DE GUERRILHAS
}

\section{Francisco Weyl Universidade do Porto}

\section{Resumo}

Este artigo reflete questões artísticas, políticas, antropológicas e identitárias, que atravessam ações culturais em comunidades periféricas e quilombolas da Amazônia Paraense, sendo um recorte à pesquisa que desenvolvo no âmbito do Programa Doutoral em Artes Plásticas da Faculdade de Belas Artes da Universidade do Porto, tendo esta narrativa emergido das memórias de práxis transgressoras que caracterizaram resistências coletivas no cenário da arte contemporânea e da antropologia visual, particularmente nas experiências do Projeto Mola, junto a crianças, jovens e adultos em comunidades tradicionais do Município de Cametá, Pará, onde foram realizadas oficinas de Cinema de Guerrilha e outras práxis pedagógicas democráticas subjacentes à construção e à produção de obras audiovisuais, culminando-se com o surgimento da metodologia de ensino do cinema, batizada de "Caruana das Imagens".

\section{Palavras-chave:}

Estéticas de Guerrilhas; Cinema de Guerrilha; Resistência; Quilombo; Periferia.

\section{LUGARES}

Os fatos de que tratam esta narrativa aconteceram entre os anos 2012 e 2014, nas comunidades tradicionais do Mola, Tabatinga, Itapocu (ou Itapucu), Bonfim, Frade, Laguinho, Taxizal, Tomázia, e Joaba, Município de Cametá/PA (Latitude 02 $144^{\prime} 40^{\prime \prime}$ Sul; Longitude 49 $29^{\prime} 45^{\prime \prime}$ Oeste; Altitude, 10 metros), de população estimada em 129.904 habitantes (IBGE, 20110), numa Área de $3.122,899 \mathrm{~km} 2$, podendo ser acessada de diversas formas. As viagens compreendem estradas, travessias de rios, pontes e balsas, demoram entre 5 horas, se pela via rodo-fluvial - destino Carapajó-Cametá; até 12 horas, se
Abstract

"I-Margins of a Caruana between Guerrilla Aesthetics" reflects artistic, political, anthropological and identity issues, which cross cultural actions in peripheral and quilombola communities in the Paraense Amazon, and is an excerpt from the research developing under the Doctoral Program in Visual Arts at the Faculty of Fine Arts of the University of Porto, this narrative emerged from the memories of transgressive praxis that characterized collective resistance in the contemporary art and visual anthropology scene, particularly in the experiences of Projeto Mola with children, youth and adults in traditional communities in the municipality of Cametá, Pará, where Guerrilla Cinema workshops and other democratic pedagogical praxis underlying the construction and production of audiovisual works were carried out, culminating in the emergence of cinema teaching methodology, called "Caruana das Imagens".

Keywords:

Guerrilla Aesthetics; Guerrilla Cinema; Resistance; Quilombo; Periphery

pela via fluvial - por barcos que saem dos portos da capital Belém, há 236 quilômetros do núcleo urbano de Cametá.

Viagens (travessias) se inserem nos processos da criação, sendo fontes das quais jorram o próprio conhecimento. É quando "o investigador torna-se presente desvelando ou mostrando a experiência do antropólogo no terreno" (RIBEIRO, 2005). Há deslocamentos que desafiam, e distâncias que aproximam, ainda que sejam obstaculosos e acidentados. Durante estes atravessamentos, lampejos podem vir a ser utilizados nos processos de pesquisas e práticas, como se formassem um oásis interior que o encontramos quando, 
solitários, caminhamos os próprios desertos. E o tempo-espaço entre o ponto de partida e o ponto de chegada do conhecimento torna-se um percurso no qual somos convocados a nos reinventar, na dialética existencial, para que possamos mais aprender do que "ensinar". A construção do pensamento resulta da combinação de fatores que também nos são alheios e que se relacionam a afazeres que realizamos de modo automático. Muitas vezes, ignoramos situações cotidianas, entretanto, pequenas rotinas têm grande importância na organização das atividades. Sentimentos e sensações diante de determinados fatos, desde os mais banais até aos de grande valor, interferem na criatividade. Boletos a pagar, engarrafamentos, consultas médicas, idas à padaria, almoços, amores ou dores, não são ações que devam ser negligenciadas, ao contrário, são úteis à experiência.

A vida também é composta de pequenas coisas - não narradas -, cujo valor é inestimável para a História, onde os fenômenos possuem causas objetivas e subjetivas, sob o domínio do racional e/ou do sensível. Considerando que a educação envolve um complexo processo, há que respeitar as diferenças locais, os atores e os espaços onde estas experiências pedagógicas são realizadas, para que não sejam aplicadas regras inadequadas, sem validade, portanto, há que se inscrever a narrativa da inequívoca experiência pessoal a partir das relações simultâneas, com o fenômeno que se observa - e se vive, e com os leitores (RIBEIRO, 2005b), fazer leituras, revisar teorias, questionar e testar metodologias, conforme pactos estabelecidos em práxis pedagógicos.

\section{TERRITÓRIOS}

Comunidades, comunidades quilombolas,
comunidades tradicionais, territorialidade, são algumas expressões aqui utilizadas, sem nenhuma intenção de Ihes definir conceitos, ainda que estejam imbricadas umas às outras, entretanto, para efeitos de compreensão da natureza deste artigo, sirvo-me de ideia de território como "passagem da memória social" (ACEVEDO \& CASTRO, 1999).

Territórios são lugares específicos, onde se desenvolvem as ações das gentes que habitam um espaço composto por "sujeitos que dinamizam os lugares, os espaços, os modos de vida, as formas de convivência múltiplas, as relações culturais e de grupo" (POJO, 2017), sendo a "comunidade" um espaço em construção dialética, a partir das relações estabelecidas entre as pessoas que a habitam (e que nela circulam/transitam), mediante interesses pessoais e coletivos, culturais, econômicos, sociais; e, sob a dimensão geográfica, delimitada e determinada pela extensão de terra que ocupa, consequentemente, as comunidades quilombolas descritas neste artigo estão em processo de construção identitária do próprio "ser-social quilombola". E esta construção implica políticas públicas, decretos de reconhecimentos de direitos a terra, e "autodeclarações" e/ ou afirmações das identidades (quilombolas), tradicionais em essência, na medida em que as culturas nelas praticadas remetem aos ancestrais que as originaram, mas que se hibridizaram no decorrer dos tempos, por interesses e pressões de grupos políticos e econômicos, entretanto, a expressão "autodeclaração" (quilombola), pela sua natureza histórica e cultural, prescinde, ainda que dependa destes Marcos Legais.

\section{CINEMA}

Esclarecida a questão "territorial", adentro nas experiências antropológicas e artísticas desenvolvidas nestas comunidades - de casas isoladas, distantes (e ao mesmo tempo próximas) umas das outras, pois demarcam pontos de referências a partir do que cada um produz para a própria sobrevivência da comunidade. Por exemplo, a produção da mandioca, da qual derivam a farinha d'água, a farinha de tapioca, e o beiju cica, serve tanto para a subsistência das famílias, quanto para a venda no mercado local, e na feira do Joaba, que acontece aos domingos, e onde foram desenvolvidas ações de Cinema de Guerrilha que mais à frente me deterei.

Quando as pessoas assistem a um filme, realizado por jovens originários destas comunidades, elas raramente imaginam os acontecimentos que sucedem para que o filme seja concebido, produzido, realizado, e projetado, e nem compreendem a grandeza criativa ali emergente ante a precariedade e as frágeis estruturas destes povos. Um filme envolve a comunhão de diversas pessoas no processo de construção criativa, desde o pensamento (a ideia) até a construção do roteiro, personagens (se ficção), produção e 


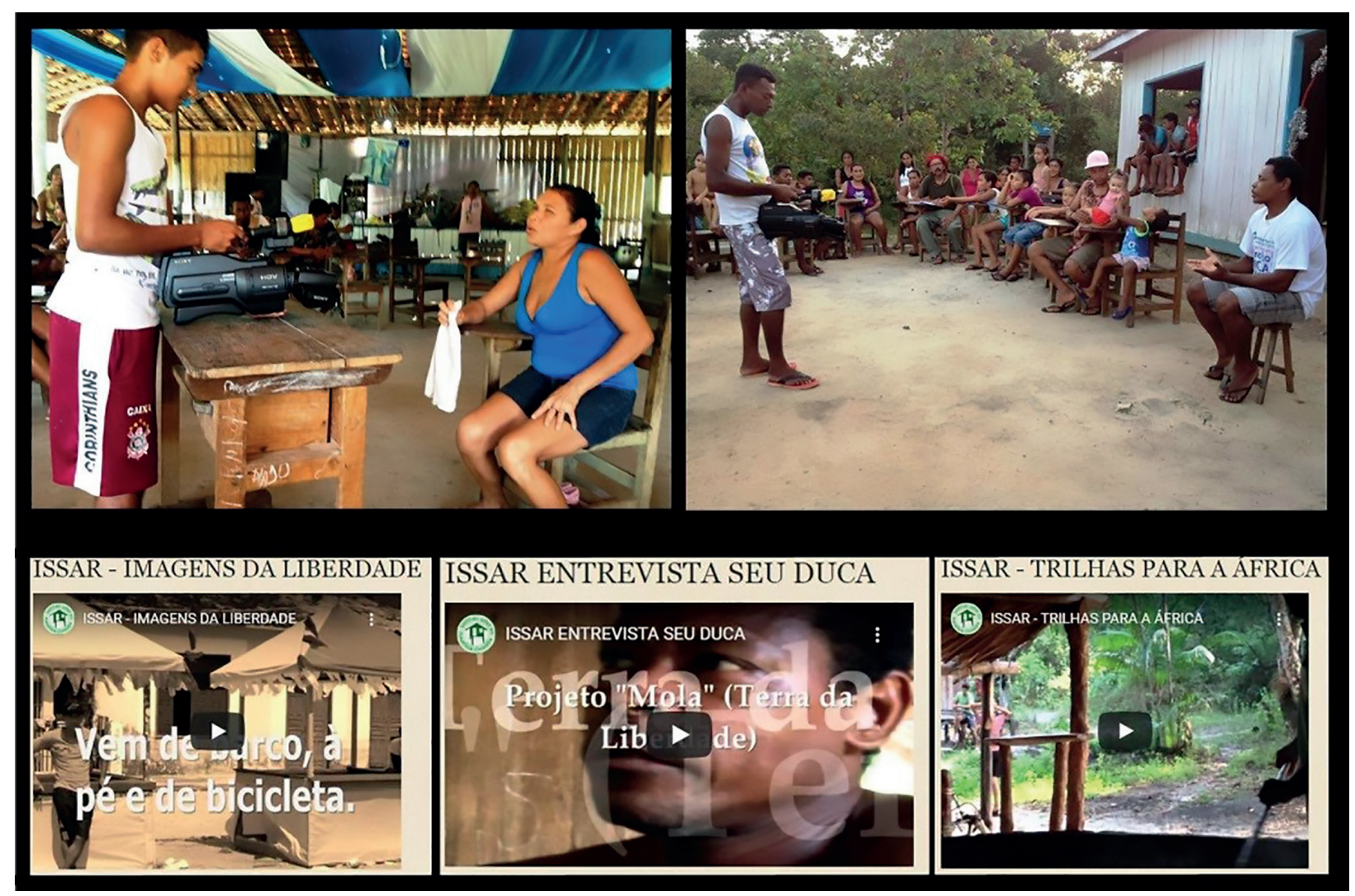

Figura 1 - Cenas de oficinas e frames de filmes realizados (Cinema de Guerrilha/ ISSAR/Dri Trindade)

realização, ainda mais em experiências coletivas como estas aqui abordadas, com sonhos, delírios, utopias, diferenças a lapidar, relações a maturar, desde a criação ao "arranjo" das cenas e dos ambientes, até que o filme seja, enfim, produzido, realizado, montado e projetado. $E$ quando fazemos este percurso num lugar onde falta o essencial, a criação tem de ser superior à ausência de estruturas, e o filme um ato libertário e social, que manifesta a relação do ser com a sociedade e a sua história.

Um exemplo desta experiência ocorreu na comunidade da Vila de Joaba, onde treze jovens e adultos, quilombolas de Itapocu e Tabatinga, que nunca haviam filmado, realizaram as "Imagens da Liberdade" ${ }^{11}$, entretanto, o filme raramente será assistido e muito menos será considerada como "obra" pela "crítica", cuja referência é padronizada pela "sociedade do espetáculo" (DEBORD, 1967), que valoriza mais a técnica do que a poesia, mais o mercado do que a história, mais a instituição do que a solidariedade, mais a mídia do que o conhecimento, mais o resultado e menos o processo, subordinando os indivíduos à condição de passivos consumidores de imagens aquém do Real.

Em nosso entendimento, a não-recepção "crítica" desta e de outras obras realizadas em comunidades periféricas e quilombolas é proporcional ao colonialismo cultural local/ regional, ao serviço do Capital global, que inviabiliza o pensamento, a práxis, e a criatividade de realizadores do cinema na Amazônia paraense, que agem nas trincheiras destas comunidades quilombolas, , nas suas diversas trajetórias, com os seus diversos tipos de saberes, permeados pela ancestralidade (ALVES, 2019), mas sem descurar dos paradigmas que constituem 0 cinema enquanto sistema de signos - e linguagem artística, o que exige reflexão além da tela em que as imagens são projetadas. Portanto, utilizaremos os paradigmas ${ }^{2}$ das "Estéticas de Guerrilhas"3 para tratar estes filmes coletivos realizados por crianças, jovens e adultos quilombolas que não possuíam nenhuma experiência com o fazer cinematográfico - e dos processos criativos 
e procedimentos metodológicos, aspectos históricos e antropológicos a eles agregados, considerando, entretanto, que guerrilha é um movimento que acompanhou o percurso da arte e da sociedade (OLALQUIAGA, 2019), expandindose, entretanto, além dos conceitos que a limitaram a uma ação armada, preconizada por alguns movimentos políticos e artísticos das décadas de 1960 e 1970, aos quais não iremos aqui recorrer, sob pena de desviarmos o foco do presente texto.

\section{ESTÉTICAS DE GUERRILHAS}

Não existe uma agenda ou um programa mínimo das "Estéticas de Guerrilhas", entretanto, elas são rizomas originários de movimentos organizados e/ou espontâneos que ocorreram ao longo da História da Arte, tendo sido destacados por pesquisadores e críticos, desde os princípios do Século XX, e que atravessam dadaístas, futuristas, surrealistas, concretistas, etc., até aos coletivos modernos e pós-modernos que, de certa forma, reviveram os ideais de vanguardas dentro e fora de espaços tradicionais de exposição da arte e dos objetos artísticos, museus, galerias, espaços públicos urbanos, pelo que estas estéticas (de guerrilhas) são uma espécie de gérmen ou vírus que sofreu mutações neste percurso criativo da civilização, e que, na Amazônia, encontrou - além das diversas e diferenciadas formas - as encantarias ${ }^{4}$ que pulsam na Região, entre estas, os "Caruanas"5.

As Estéticas de Guerrilhas surgem como "alternativa à história da arte oficial, posto que essa última é eurocêntrica e atrelada aos convencionalismos da tradição" (CHAGAS, 2018). Numa rápida descrição das potências destas estéticas de guerrilhas, afirmamos que elas se apoiam numa díade ("poéticas da gambiarra" / "tecnologia do possível") ${ }^{6}$, segundo a qual "qualquer coisa pode ser transformada em trabalho artístico" (CHAGAS, 2018b), entretanto, limitarnos-emos a enunciar alguns tópicos abaixo, sem desdobrá-los, ainda que isso se torne necessário para uma melhor compressão deste conceito, mas que não avançaremos, em função de nosso objetivo que é o de apresentar o "Caruana das Imagens" e os processos que o constituem como uma aplicabilidade das "Estéticas de Guerrilhas".

As estéticas de guerrilhas colocam em causa a arte convencional, institucional, e acadêmica, assim como as estruturas da própria Indústria Cultural, mesmo que algumas de suas produções transitem nestes campos, através de fóruns e/ ou redes sociais, nos quais suas práticas são apagadas e/ou excluídas, quando não usurpadas por fazedores de cultura que insistem em ocupar um lugar (de fala) que não Ihes pertence.

Estas contradições são inerentes aos processos internos da própria produção destas estéticas no (seu) "lugar" de criação, por analogia e para tomar emprestada a expressão "lugar de fala", que refere ao direito exclusivo que apenas algumas pessoas têm de expressar e falar sobre a sua potência política e/ou artística, social e/ou humana, desde que "habitem" e/ou tenham nascido no interior deste "lócus" (de fala).

Mas não existe uma "violência", antes, uma conciliação ou ainda antes disso, uma conversão apolítica natural em que o criador "situado" sob o paradigma das estéticas de guerrilhas - mesmo sem esta consciência - não se move em direção à Mídia e à reverberação de seus objetos de trabalho artístico, como o fazem, por exemplo, realizadores e produtores que flertam com estas estéticas (de guerrilhas).

As "estéticas de guerrilhas" não estão em oposição a uma não-estética de guerrilha, no sentido em que a arte ocupa função política, ainda que de forma "desinteressada", muito menos tais estéticas (de "guerrilhas)" colocam-se no campo essencialmente artístico (ou político), ainda que, de forma espontânea ou dirigida, façam o enfrentamento do atual estado da arte da política. As estéticas de guerrilhas não desafiam as ditas "vanguardas" estéticas, pois que as criações a elas inerentes contém elementos desde as vanguardas até ao conservadorismo da própria História da arte, pelo que as estéticas de guerrilhas compõem conteúdos e formas, processos, métodos e procedimentos originais, mas, também, híbridos, entretanto, numa dimensão em que o criador está em contato espontâneo com a criação e a esta entregue, distante dos conceitos e das práxis à priori.

As estéticas de guerrilhas pressupõem um "prazer estético" revolucionário no sentido artístico da experimentação de fazer, o que se quer e se pode fazer a partir do que se dispõe para que seja feito, dentro de duas condições essenciais, que são a poética da gambiarra e a tecnologia do possível. As estéticas de guerrilhas não consideram uma 


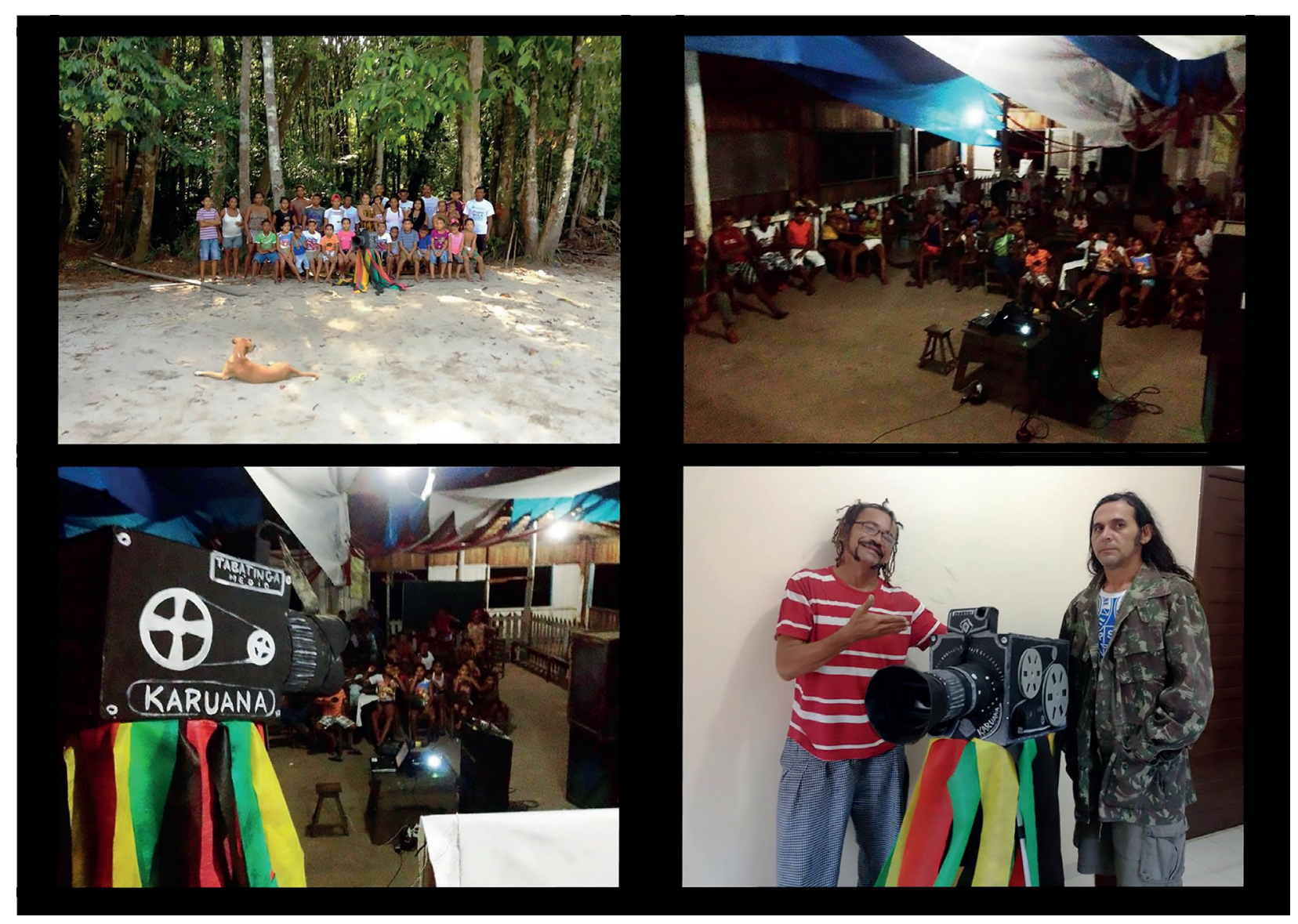

Figura 2 - Cenas de oficinas e projeções cineclubistas (Cinema de Guerrilha/ ISSAR/Dri Trindade)

guerrilha estética como o centro de sua própria gênese, ao contrário, há diferenças entre as estéticas de guerrilhas e as guerrilhas estéticas, exatamente porque a (sua) fonte de produção e/ ou de criação está muito além de um (seu) próprio campo original, não se limitando ao conceito de arte em si - e para si.

As estéticas (de guerrilhas) não são um conceito nem se pressupõem "arte conceitual", pois que a ideia de desejo a elas imanente transcende o (seu) próprio campo ("artístico"), atravessando e lançando luzes em diversos estilos e linguagens criativas às quais recorrem para se expressar nos espaços em que são produzidas/criadas por artistas/criadores para os quais, muitas vezes, nem está colocada o próprio conceito/ideia de "ser" artista.

Os artistas das estéticas de guerrilhas, portanto, estão na periferia destes signos e símbolos que constituem a construção da crítica da arte, sem a esta negar, pois que a esta ignoram, por uma necessidade de afirmação do valor do que produzem/criam e que não são "reconhecidos", na verdade, são invizibilizados, quando não apagados e/ou usurpados pelos campos nos quais a crítica transita.

A lógica do ser-artista não está pautada nas comunidades dos artistas de guerrilhas, mas sim a do ser-social, do(a) trabalhador(a) rural, da dona de casa, do estudante, pois que são pessoas que têm uma relação com o espaço em que habitam e produzem e para quem não se coloca esta (sua) condição (artística), independentemente de "ingenuidade" e/ou "espontaneidade" com a qual criam as expressões artísticas.

As estéticas de guerrilhas também não são "anticonceitualistas", no sentido em que a arte conceitual é a culminância das vanguardas ante-entre-pós-guerras do Século $X X$, porque elas operam com a precariedade do objeto artístico na ausência de um projeto institucional contra o qual se insurgem, usando os materiais 
descartados pela sociedade de consumo como armas e ferramentas para enfrentar o sistema e a indústria cultural e mediática.

Se a vanguarda executa a ideia de transformação pelo choque (FREITAS, 2007), e os coletivos operam "ações de contestação e formas artísticas não convencionais (GONÇALVES, 2010), o "papel" social da arte e do artista no campo das estéticas de guerrilhas define-se pela transgressão de valores das políticas da arte por uma arte que seja política na sua essência, mas sem a política se submeter.

\section{TERRA DA LIBERDADE ${ }^{7}$}

O Instituto Saber Ser Amazônia Ribeirinha (ISSAR) atua pela melhoria da qualidade de vida, dentro de uma dimensão histórica, étnico e cultural, com desenvolvimento sustentável, educação, saúde, economia solidária, e cultura digital, em zonas periféricas, e comunidades quilombolas, nas ilhas da Região Metropolitana de Belém e Ananindeua, e em outros municípios paraenses. O Instituto fez parcerias para executar projetos de desenvolvimento e inclusão produtiva local de setores excluídos, além da formação profissional de jovens em situação de risco social, formação continuada de professores públicos, letramento da criança ribeirinha, educação para saúde natural preventiva, apoio e capacitação de empreendedores para a Economia Solidária, entre outros projetos eco-políticos. Estas ações também estão centradas na saúde preventiva, na formação de mulheres para a difusão da medicina caseira, com apoio científico, na formação tanto de jovens em dificuldade escolar formal, quanto na educação popular.

Com raízes nos movimentos sociais e na organização dos trabalhadores, o Instituto é fruto de encontros e diálogos entre profissionais, pesquisadores, trabalhadores, lideranças políticas populares, que aliam a ideia de mobilização política, com a produção da memória na relação da construção do território (ACEVEDO \& CASTRO, 1999b). Sensíveis à construção de um mundo solidário, estas mulheres e estes homens das mais variadas origens e etnias desenvolveram o Projeto Mola ${ }^{8}$, do qual participamos como formador, entre 2012/2014, nas comunidades do Mola, Tabatinga, Itapocu (ou Itapucu), Bonfim, Frade, Laguinho, Taxizal, e Tomázia, Joaba, todas localizadas no
Município de Cametá/PA, e que evolveram cerca de mil pessoas, entre as quais, cerca de duzentas e cinquenta crianças e trezentos adolescentes.

Um dos coordenadores do Instituto, o pesquisador Hilton P. Silva ${ }^{9}$, informou que pesquisas revelaram que a pesca do camarão, a caça de animais, e atividades de agricultura familiar (principalmente a produção da mandioca), constituem a base de sobrevivência das comunidades envolvidas no projeto Mola, entretanto, estas comunidades enfrentam problemas relacionados à produção de bens e ao seu escoamento, já que são precárias as estradas e as estruturas de transporte, sendo carentes de produtos alimentícios, com dificuldades de acesso à renda, sem dispor de infraestrutura sanitária, falta-Ihes assistência à saúde, com o registro de elevado número de casos de doenças infecto-parasitárias, especialmente em crianças, mas também, doenças crônicodegenerativas, com maior prevalência entre mulheres adultas.

Por isso mesmo, o projeto abrangeu indicadores subordinados aos princípios da cooperação e da sustentabilidade, entre os quais: identidade (identificação/condução da descoberta/ construção da identidade sócio-étnicocultural-econômica das comunidades); direitos (apoio a organização sócio-política, estímulo ao protagonismo e autonomia política às comunidades no exercício de controle social); e qualidade de vida (produção e consumo em sinergia com a economia local e regional, promoção e incremento de renda, a partir da identidade sociocultural). Tendo como foco principal crianças, adolescentes e mulheres, trabalhados a partir de três componentes operacionais, o projeto desenvolveu estratégias operacionais flexíveis como: capacitação/formação/organização sócio-política e articulação interinstitucional; e envolveu/estimulou o protagonismo infantojuvenil; e a participação da comunidade em ações de resgate e de valorização das tradições, voltadas para a cultura, à educação, à economia solidária, e à sustentabilidade socioeconômica e ambiental.

Desde 1635, quando foi fundada que a Vila de Cametá, possui "papel ativo na história da colonização portuguesa na Amazônia" (ACEVEDO \& CASTRO, 1999c), constituindo um potencial estratégico territorial e florestal em função da 
proximidade com a foz do Rio Pará, entretanto, atualmente, o envelhecimento dos adultos que permanecem isolados nestas comunidades, e a perda das manifestações culturais, danças, e ritmos, são ameaças constantes as maneiras pelas quais os grupos sociais autodefinem identidades e etnias culturais, e afirmam as diversidades, resultantes da confluência de fatores como ancestralidade, elementos linguísticos e religiosos, sendo esta "identidade" a base para a organização e relações entre comunidades, num processo complexo, que não pode ser reduzido a fatores materiais ou traços biológicos distintivos, como, por exemplo, a cor da pele.

Portanto, o conhecimento, a cultura e o emprego da mão-de-obra negra tiveram grande importância para a economia amazônica (SALLES, 1971). Os escravos negros foram utilizados em atividades agrícolas e extrativistas, nos trabalhos domésticos e nas construções urbanas. A história da escravidão no Pará tem a marca da resistência de negros e índios pela liberdade, por meio da fuga, da construção dos quilombos e da participação na Cabanagem.

\section{I-MARGENS}

As populações quilombolas destas comunidades estão vulneráveis do ponto de vista histórico, social e econômico, razão pela qual estas pesquisas se tornam necessárias para aprofundar o conhecimento sobre estes povos, no sentido de contribuir para a construção de políticas públicas adequadas às garantias de seus direitos, que é o que, afinal de contas, o ISSAR, organizações nãogovernamentais, e pesquisadores de algumas instituições compromissados com a História da Amazônia paraense têm realizado. Mas, o paradoxo temporal é que a extensão dialética dos dias/ meses/anos em que atuamos nestas comunidades quilombolas tem dimensão reduzida pela perspectiva cronológica, portanto, a despeito de nossas intenções e intensidades, e de nosso esforço e dedicação, este "tempo" representa apenas uma inferência num determinado fato/fenômeno, mas, não o fenômeno, em si mesmo, até porque não podemos generalizar o quotidiano comunitário, resumindo-o ao período de nossa estada entre as gentes quilombolas, ainda mais se pensarmos no poder simbólico destes cenários e ambientes da Amazônia paraense, considerados exóticos quando expostos em imagens fotográficas e/ou videográficas em espaços e/ou sessões acadêmicas e/ou mediáticos, razão pela qual valorizamos o direito ao uso de imagens e defendemos a criação de uma Lei de Royalties culturais, que destine recursos financeiros para pessoas/coletivos que se tornam tema e/ou cenários de fotos e/ou filmes de "autores" que não têm a menor responsabilidade ética e/ou social com as pessoas e/ou comunidades envolvidas em suas "criações" culturais, algumas das quais a circular e/ou pulverizadas em galerias, publicidades e redes sociais, utilizadas com o poder da comunicação imagética na cena contemporânea, em função do impacto e da força expressiva evocada, sem que que estas culturas sejam por isso mesmo "compensadas".

Muitas destas "imagens", entretanto, ficam impregnadas na memória do pesquisador que as captura com os olhos e as (d)escreve, com a imaginação, construída nos diálogos com as pessoas com as quais estabelece relações nestas comunidades, onde há alternâncias entre os poderes dos "lugares de fala e de escuta", pertencendo ao território/espaço do compartilhamento e da troca subjetiva entre sujeitos-atores sociais que se disponibilizam aprender um com o outro pelas suas diferenças, preservadas por narrativas orais que são a própria essência das ancestrais formas de transmissão de conhecimentos nestas comunidades, sendo este fenômeno mais metafísico do que científico, mais natural do que conceitual.

Entretanto, não se trata aqui de tentar dar sentido a uma nova etnografia - de um (ser) "estranho" à pesquisa, que observa, colhe informações de fontes, e de informantes, mas, que está distanciado do espaço pesquisado, ainda que nele inserido, antes ao contrário, esta "escuta" constitui uma diluição no espaço da ação da própria pesquisa, sendo ela já própria pesquisa em si, e ao mesmo tempo o seu apagamento, pressupõe acolhimento, simultâneo, entre quem escuta e aquele que fala - se deseja falar, sem que seja (estranhamente) "observado", pois que as memórias destas comunidades são menos arborescentes e mais rizomáticas ${ }^{10}$, ainda que algumas pesquisas as erijam como blocos monolíticos fechados em "objetos" científicos.

Em tempos de ventos fortes, e águas altas, há uma forte sensação de que tudo é contracorrente, 
entretanto, remamos o barco menos como timoneiro, e mais como um anônimo navegador. $\mathrm{E}$ aprendemos com os fluxos dos canais, e os bancos de areia, a subir e descer, em favor ou contra a maré, a depender, se em direção ao Carapajó ${ }^{11}$, ou no rumo do porto de Belém. Mas, basta transpassar as águas do Tocantins e da Baía do Guajará para saber que, em Cametá, há povos ribeirinhos, povos das águas, povos das florestas, cujas narrativas estão impregnadas de símbolos próprios, sendo o caboclo cametaense ensimesmado e desconfiado, porque sofreu e ainda sofre e aprende com este sofrimento a se defender dos ataques à sua cultura. E uma das coisas que percebemos nas oficinas de Cinema de Guerrilha é que, em Cametá, as coisas têm um tempo próprio. Muito próprio. E este "tempo" aqui referido, ele só decorre e se encerra num único espaço, qual seja o das águas que margeiam as comunidades quilombolas. É, portanto, um tempo líquido, que se altera "muito rapidamente, sob a menor pressão" (BAUMAN, 2006), mas que resulta de um processo histórico de colonização, e de opressão, que começou com a chegada do primeiro homem branco à Região, e que persiste ainda nos dias atuais, com valores que se perpetuaram e adquiriram as requintadas formas da exploração contemporânea do homem pelo homem, pelo que as oficinas de Cinema de Guerrilha, aqui descritas, proporcionaram um encontro com estas paisagens e com os sentimentos destas populações, cuja dialética, ainda agora estamos a aprender. E a escrever.

\section{QUILOMBOS}

A memória destas comunidades começa a se dissipar, na medida em que a juventude cede ao assédio da contemporaneidade e aos objetos de desejo por ela anunciados em publicidades via mídias, canais de televisão, programas radiofônicos, redes sociais, razão pela qual a juventude se desinteressa das raízes culturais da comunidade, conforme declarou um dos quilombolas mais antigos do quilombo "Mola", Senhor Coelho (também conhecido por "Seu Pina"), em entrevista a um dos documentários produzidos nas oficinas de Cinema de Guerrilha do projeto Mola12. Em Tabatinga Média, o "samba de cacete"13 sobrevive apenas no imaginário e nas memórias dos mais velhos, enquanto a juventude local se deixa absorver pelas novidades publicitadas pelo mercado, as quais ela "deseja" consumir. Esta comunidade tradicional de Tabatinga tem cerca de sessenta famílias (em média trezentos habitantes), é dividida em Tabatinga Média, Boca (mais próximo de Joaba, que é a comunidade mais desenvolvida), e Tabatinga de cima (esta área, pertencente ao município de Mocajuba), sendo o quilombo "Mola" o "mais antigo", fundado, de acordo com relatos, nos anos 1750, localizando-se numa zona de difícil acesso, carente de estruturas, consequentemente, ressentindo-se da migração da juventude para o núcleo urbano de Cametá, e/ou lugares vizinhos, como indicou-nos "Seu Pina". No Mola, há apenas uma Escola, vinculada à Secretaria Municipal de Educação de Cametá, com uma professora que atua numa única sala de aula multisseriada para crianças entre 5 e 12 anos de idade, desde o Jardim I a 4( série do Ensino Fundamental. É desafiante, portanto, identificar estas dinâmicas sociais, políticas, e econômicas, para percebermos melhor como estabelecer relações com as gentes deste lugar no âmbito de um processo pedagógico que resulta na organização de coletivos audiovisuais, entretanto, cabe aos próprios quilombolas o protagonismo destes processos, pelo que estas ações são dialógicas entre os atores sociais dos espaços onde são desenvolvidas, e de onde emanam as demandas de cujos processos e resultados eles se empoderam.

Até o ano de 2015, a Fundação Palmares, na altura vinculada ao Ministério da Cultura (extinto em 2019) havia certificado 2471 comunidades remanescentes de Quilombos, 227 no Estado do Pará, sendo este ato o primeiro Marco Legal à obtenção do Título da Terra pelas Comunidades Quilombolas, processo executado pelo Instituto Nacional de Colonização e Reforma Agrária (Incra), que, entretanto, regularizou apenas 190 comunidades, 60 delas no Pará, que é um Estado com mais de 300 comunidades tradicionais autodeclaradas quilombolas, sendo que cerca de 70 delas estão no Vale do rio Tocantins, onde apenas 11 foram legalmente tituladas. O pesquisador Manoel Valente ${ }^{14}$, que participou do projeto Mola, informou que o Vale do Tocantins abrangia desde o município de Limoeiro do Ajuru até Tucuruí, e que somente pelo século XVIII é que surgiram Baião e Mocajuba, portanto, muitos negros subiam os rios e se deslocavam para esta Região. Com cerca de 


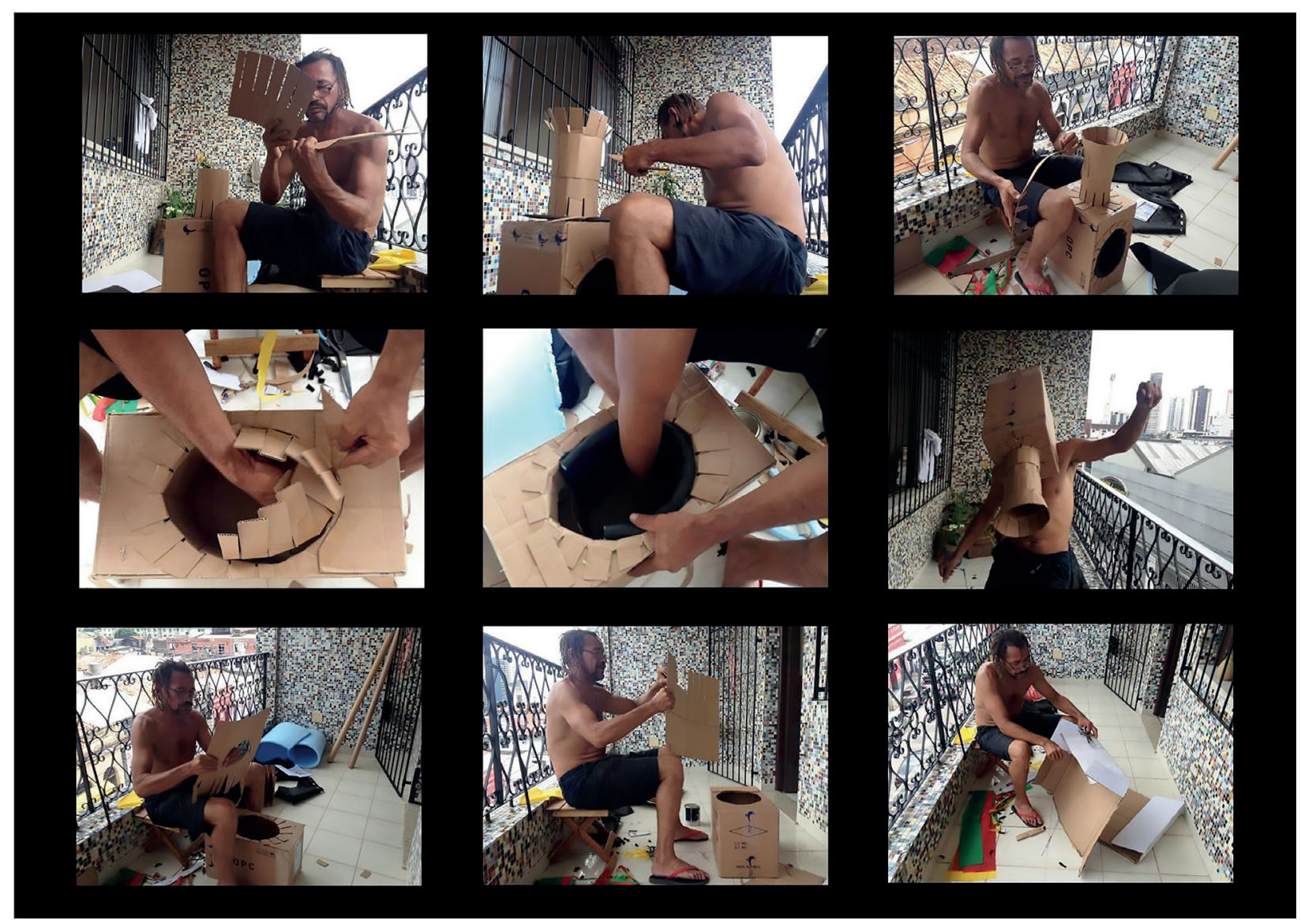

Figura 3 - Artista Cuité na construção do "Caruana das Imagens" (Cinema de Guerrilha/ISSAR/Dri Trindade)

$60 \%$ da população autodeclarada negra, portanto, a cultura da região Baixo-Tocantins, no nordeste paraense, tem ascendência africana no sangue, na língua e na cultura.

Entre idas e vindas, entretanto, percebemos que 0 sentimento de pertencimento regional se altera a todo o momento pelos interesses da elite, que dita políticas públicas para a cultura, principalmente quando estas são aliadas aos interesses da indústria cultural, que ora apaga, ora usurpa a produção cultural destas comunidades, tratandoas como folclore, hibridizando-as, fragilizando-as, desqualificando-as, introduzindo nos quilombolas um sentimento psicológico de frustração e/ou alienação. E onde o Estado chega com políticas pela sociedade demandadas, ele também se torna um destruidor dos processos culturais, enquadra as lógicas estéticas, e privilegia grupos nucleados no interior de seu sistema, institucional e mediático.

Não se trata, entretanto, de disputar este Poder, ou a (sua) gestão administrativa de recursos financeiros, mas de entender que nestas relações entre institucionalidades e práticas culturais periféricas (de guerrilha - e de resistência), estas "distantes" comunidades, "intocadas" pelas políticas de Estado, seja na área urbana ou rural, têm de ter direito ao acesso à produção, à difusão, e ao consumo dos bens culturais, dos quais também são criadores, e como tais têm de ser reconhecidos, ainda que estejam excluídos dos mecanismos "disponibilizados" pelo Estado, e - por ele - invisibilizadas. A sociedade consumista investe no que se parece com - ou o que é aceito pelo - circuito artístico globalizado, colonizador, eurocêntrico, institucional, castrador, que difunde a desconstrução, anula, e diminui o processo agregador e a potência das culturas destas comunidades tradicionais e quilombolas, nas quais atuamos com o espírito transgressor, usando as próprias armas do opressor - contra a opressão, construindo com parafernálias tecnológicas precárias, a tecnologia do possível, as poéticas das gambiarras, e as estéticas de guerrilhas. 


\section{AS OFICINAS}

Desenvolvidas entre abril de 2013 e dezembro de 2014, no âmbito do projeto Mola, as oficinas de Cinema de Guerrilha consistiram na produção de vídeos de baixo orçamento, e tinham como perspectiva introduzir e formar crianças e jovens a partir dos 14 anos nas linguagens da arte cinematográfica, com base em teorias e técnicas cinematográficas. A meta das oficinas era a produção, a realização, a edição digital, e a projeção, de um conjunto de projetos audiovisuais que também se tornassem materiais paradidáticos, sobre saúde, educação, economia solidária, e identidades étnicas e culturais, temáticas de interesse do projeto coordenado pelo ISSAR. Foram realizadas três oficinas de Cinema de Guerrilha, e diversas sessões cineclubistas, entre outros eventos paralelos, articulados ao projeto, em diferentes comunidades, com as quais foram dialogados e avaliados processos e dinâmicas que resultaram em filmes coletivos realizados por crianças, jovens e adultos que participaram das oficinas.

\section{OFICINAS DE CINEMA DE GUERRILHA}

- Teorias e práticas audiovisuais

- Produção e montagem de filmes (durante o Festival de Cultura do Joaba)

- Produção e montagem de filmes

\section{FILMES REALIZADOS ${ }^{15}$}

FICÇÃO

- Imagens da Liberdade (Digital, Cor, 8 min, 2013)

ENTREVISTA

- Issar entrevista seu Duca (Digital, Cor, 7 min, 2013

- Issar entrevista Bruno Sechi (Digital, Cor, 6 min, 2013)

SÉRIE (Trilhas para África/DocFicção)

- Diálogo com seu Duca a caminho da farinhada na casa do Osvaldo (Digital, Cor, 7 min, 2013)

- Caminhos quilombolas (Digital, Cor, 8 min, 2014)

- Jogo aberto em Tabatinga (Digital, Cor, 4 $\min , 2014$ )
DOCUMENTÁRIO

- Memórias do Senhor Coelho (Digital, Cor, 15 min, 2014)

VÍDEO-ARTIGO

- Colóquio Antropocine (Digital, Cor, 12 min, 2020)

Sem descurar as particularidades que marcam as escolhas dos filmes, articulação e preparação do espaço, organização e divulgação da atividade, e a responsabilidade de diferenciar a projeção pública de um filme de uma ação de guerrilha (cineclubista) - o que envolve princípios éticos, estéticos, artísticos e políticos -, podemos afirmar que o Cinema de Guerrilha é por extensão a aplicação específica do conceito das Estéticas de Guerrilhas ao cinema e à linguagem cinematográfica, compreendendo a intervenção da ação do ser social com o audiovisual no âmbito de projetos coletivos no espaço urbano e rural, sendo ainda determinado pelas relações geradas entre criadores, comunitários, e passantes sensibilizados pelas projeções públicas e pelas temáticas evocadas pelos filmes (projetados), bem como pelas possibilidades de criação e de realização de novas guerrilhas potencializadas pelos encontros que estas sessões provocam.

O Cinema de Guerrilha, neste sentido, é tanto o filme quanto a práxis do realizador, sendo o momento da projeção aberta, e na maioria das vezes despojada dos sistemas de produções culturais, o espaço de representação e da contradição, do diálogo e da roda, do silêncio e da palavra, o lugar da ascese da resistência, onde a imagem se torna a narrativa do corpo coletivo, e a fala, comunitária, reverberada e revestida de sentidos que se tocam e se trocam pela experiência intuitiva e sensível de realizadores, criadores, comunitários, e passantes, dentro de um "tempo" cuja passagem é marcada pela dinâmica da realidade do acontecimento e da instalação das gambiarras estéticas que alimentam a tecnologia do possivel.

Além de documentários ensaiados e ficções sonhadas, o Cinema de Guerrilha é um ato que traduz uma potência imaginária que ele transporta como um fenômeno que se instaura no processo das substâncias das quais é originado e ao mesmo tempo emana, portanto, o Cinema de Guerrilha 
é - deste a criação, a produção, a realização, a montagem, a projeção até ao apagamento da obra fílmica - o que o torna real como uma ação que reúne pessoas em praças e ruas, comunidades e florestas, sob o espírito da resistência estética e política. E os coletivos de Cinema de Guerrilha surgem, nestas oficinas, com a missão de pensar, produzir, filmar, e montar um filme, no qual todos são os realizadores, sendo que os participantes são convocados a refletir sobre as manifestações culturais locais, das quais eles próprios são os protagonistas, pelo que a ferramenta da imagem se torna um referencial para esta análise. Nesse sentido, o protagonismo da juventude quilombola nas oficinas de Cinema de Guerrilha se opõe ao paradigma segundo o qual as produções acadêmicas e artísticas sobre a Amazônia são fabricadas de fora para dentro.

\section{LINGUAGENS}

Em Cametá, a nossa experiência atravessou diversas modalidades de linguagens, passamos da oralidade à escrita, mediante composições (iniciais) cinematográficas, desde o "filme-falado" (imaginado), a partir de práticas intrínsecas à cultura local (a tradição de passagem oral dos conhecimentos) - para o filme (d)escrito, pela via de exercícios construtivos das ideias e dos story lines inventados pelos jovens participantes das oficinas audiovisuais. A partir de suas próprias narrativas, portanto, e de suas "falas" (de seus lugares de falas), desde as primeiras entrevistas, nas quais eles revelavam "desejos" de filmar o "lugar" em que habitam, realizando o que denominamos de "transfusão signica", ou seja, desde os signos verbais/orais, e/ou (posteriormente) signos gráficos, que se re-significam (em) audiovisuais, durante as práxis cinematográficas, desenvolvidas. Todos os conteúdos produzidos pelas oficinas de Cinema de Guerrilha em Cametá foram disponibilizados na Internet, de forma a potencializar compartilhamentos e outros diálogos com estas poderosas ferramentas virtuais que reverberaram estas ações afirmativas e sustentáveis.

Tais processos estão localizados na esfera da imagem e do imaginário, amazônidas, sendo imagéticas as pesquisas e práticas em arte (cinematográfica e fotográfica) daí advindas, razão pela qual os resultados das oficinas de Cinema de Guerrilha resultam em filmes coletivos. $E$, ao mesmo tempo em que o arte-educador se entrega de corpo e alma ao projeto, ele também se distancia para obter uma ampla visão (autocrítica) das metodologias didáticopedagógicas operadas, se estas são dinâmicas para implodir/explodir novos valores nas consciências dos participantes das oficinas. Reunir pessoas de diferentes concepções de vida, sexos e orientações sexuais, idades, e desejos requer equilíbrio para suportar provações e tensões, sendo as pessoas diferentes umas das outras, e cada cabeça, uma sentença, cada vida, multiplicidades, rizomas, portanto, os coletivos necessitam destas fricções entre as individualidades.

Os participantes das oficinas de Cinema de Guerrilha exercitam a sua capacidade de liderança ao (se) perguntar e responder, a si-e uns aos outros -, as mesmas questões que também colocam à comunidade da qual fazem parte, numa partilha dialética e histórica. E assim, articulam-se os desejos temáticos às (suas) realidades, agregamse (auto)demandas às questões da comunidade, e são identificadas como se processam as relações de Poder no espaço local. E neste caldeirão, que o pesquisador-orientador das oficinas faz mapas temáticos, identifica intenções e interesses, localizem pontos de conexão, mostra-Ihes miniprojetos, prepara exercícios de câmera, acompanhados de orientações teóricas sobre funções, estilísticas, e dramaturgias, cinematográficas. E leio atentamente o que (d) escrevem, bem como Ihes dou "toques" literários, teatrais, cinematográficos, detalho algumas possibilidades de articulação entre as (suas) ideias, diferencio, busco unidades entre o que (eles) pensam, narram e escrevem, avalio as narrativas orais e como cada uma delas "detalha" (suas) histórias, com ênfase em observações literárias e estéticas, evidenciando os aspectos ilusórios das linguagens oral, gráfica, teatral, audiovisual, e apontando como as pessoas iludem e podem ser manipuladas pelo modo de falar, silenciar, e pelo jeito de expressar o corpo. Cruzo (suas) falas com elementos teóricos e históricos do cinema, articulando-as a outras artes, como a pintura, e a fotografia, então, projeto as entrevistas realizadas, e as imagens capturadas por cada um dos participantes, para que as analisem, autoanalisando-se; falo sobre produção, seus componentes, e etapas, apresento 
elementos técnicos, o som, a luz, ao mesmo tempo, que relaciono tais aspectos à cultura local, ao cotidiano da comunidade, festas, tradições, e causos; mostro filmes que considero significativos, obras desde a origem até as vanguardas do cinema, documentários com temáticas sociais, e amazônicas, com os quais se identificam. E Ihes entrego a câmera, e eles brincam, com escalas e massas de planos, e os objetos, e cenários, no contexto do quadro capturado, como um cinematógrafo dos irmãos Lumiere, mas também como armas de propagando de uma Revolução, como a Soviética.

Enquanto instalo equipamentos, conecto cabos, e busco um cenário tecnicamente favorável a captura de cenas e entrevistas, destaco a importância destas ações aos participantes das oficinas como se operasse uma máquina de guerra. Faço-os ver que um filme está a ser realizado paralelamente a outro filme e que cada ação real possui uma força própria para um coletivo cinematográfico. E Ihes narro o meu deslocamento até ao espaço em que estamos a fazer os exercícios, desde o ir e vir, de casa, algumas vezes a pé, outras, de bicicleta, ou de motocicleta, falo-Ihes que todos os dias pela manhã eu olho pela janela o cotidiano das pessoas e que aquele fato tem um significado próprio e em si mesmo e que possui uma força poética diferente da natureza do meu olhar. Tento fazer com que compreendam e se sensibilizem ao fato de que é o projeto que se adequa à realidade e não esta que se adéqua ao projeto. $E$ todo este percurso se faz como um desenho em uma caverna escura, cuja imagem final, você intui, mas não sabe ainda com o que de fato ela se parecerá, pois que depende individualmente de cada um dos participantes das oficinas e do sentido de coletivo que a mesma desperta em cada um.

A dinâmica desta vivência provoca o envolvimento mútuo, ao mesmo tempo uma espécie de consenso, e dissenso, quanto a definição dos papéis que cada um desempenha, como se o abstrato se tornasse concreto, ou o caos se ordenasse com a estranha leveza de sua violência. Dessa forma, os miniprojetos se constroem, coletivamente, em várias frentes de trabalho, mas há ainda muitas nuances que escapam às memórias pedagógicas, e que certamente repousam no inconsciente do conhecimento, de onde afinal de contas emanam as potências da criação.

\section{CARUANA DA IMAGENS}

Algo de novo nasceu no coração da floresta amazônica. Cerca de 30 jovens e adultos quilombolas que participaram das oficinas de Cinema de Guerrilha em Cametá afirmaram direitos históricos pela via de processos coletivos e democráticos, através das linguagens artísticas com as quais realizaram filmes de curta e média-metragens, com equipamentos digitais, em que narram as próprias histórias, revelando, portanto, que as dinâmicas dos "exercícios" audiovisuais praticados nas oficinas de Cinema de Guerrilha não estavam isolados das realidades cotidianas das comunidades nas quais elas ocorreram, antes ao contrário, elas envolviam permanentemente os atores sociais nas suas atividades. Consequência direta disso é que alguns participantes das oficinas assumiram responsabilidades diretas na operação de câmeras e captura imagens, em apresentações culturais, inclusive em outros eventos culturais da comunidade.

Estas oficinas de Cinema de Guerrilha constituem uma prática educativa cuja metodologia é direta, e agregada ao espaço em que são desenvolvidas, por exemplo, em Tabatinga Média, no momento em que os voluntariosos Agentes de Saúde pesavam as crianças no "barracão" da comunidade, as mães os entrevistaram como parte de um exercício fílmico. Além deste, outros exercícios geraram uma diversidade de imagens que revelaram a poética dos jovens realizadores, sensíveis à dinâmica dos trabalhadores rurais e pescadores da comunidade local. A participação nas oficinas estimulou os participantes destas a se interessar em ocupar e ampliar espaços - no campo das tecnologias -, consequentemente nas redes, produzir as próprias informações e imagens a partir do seu lugar de fala, e a reverberar a realidade em que vivem para alcançar mais apoio às suas demandas, e escapar do anonimato ao qual são relegados, e afirmar a sua própria potência contra as fronteiras da invisibilidade.

No decorrer das oficinas, os participantes puderam experimentar as práticas do "Caruana das Imagens", que são metodologias de ensino da arte e da cultura visual para crianças e jovens que desenvolvemos junto com o artista Cuité ${ }^{16}$. 


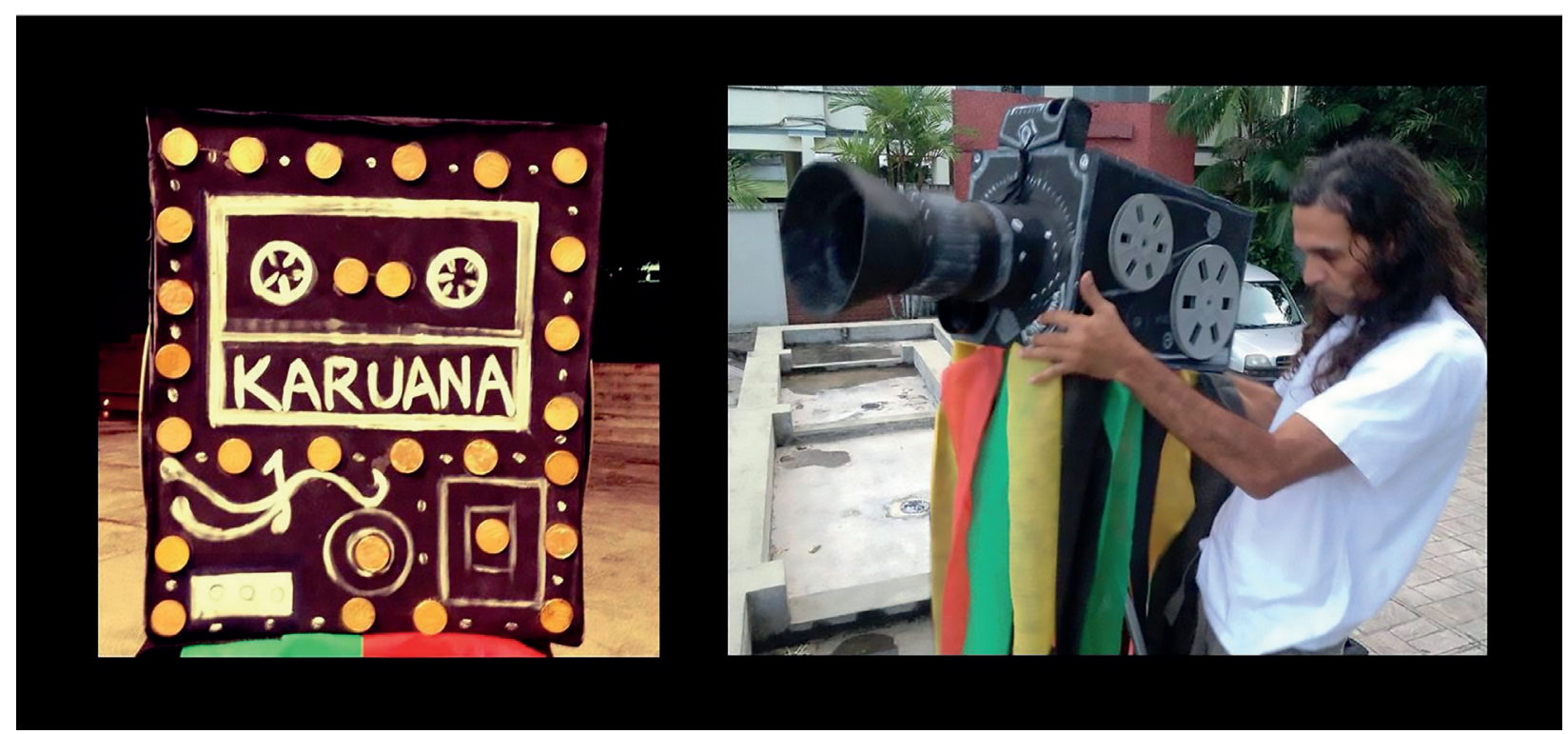

Figura 4 - O pesquisador Francisco Weyl com a "Caruana das Imagens" (Cinema de Guerrilha/ISSAR/Dri Trindade)

Estas metodologias resultam, inicialmente, da construção de um objeto, uma câmera de filmar, a partir da estrutura de uma caixa de papelão. Fundamentalmente, é a transformação e a ressignificação de um objeto em outro. A caixa de papelão (que só tem função de uso cotidiano ao qual se destina) se torna em câmera de filmar (que, apesar de ter uso doméstico, ocupa uma função tanto de registro, quanto de memória, e de arte, e de cultura, de uma forma global). Mas, este processo tem a matriz ecológica da reciclagem e da reutilização, pelo que ele "afronta" a sociedade de consumo e sua cultura do descarte: a câmera é construída a partir de caixas catadas no lixo, desde que em condições de uso, considerandose ainda a adequação do tamanho da mesma para que se torne no "novo" objeto. É dentro deste contexto humano e pedagógico da arte-educação audiovisual que os pesquisadores-oficineiros trabalham as eco-políticas de preservação ambiental sob o paradigma lúdico-artístico do fazer-saber.

E, assim sendo, com uso do (estilizada) "Caruana das Imagens", jovens e crianças são estimulados a, literalmente, entrar no mágico mundo do cinema. Isso porque a caixa-câmera (de aproximadamente $50 \mathrm{~cm}$ de cumprimento $\times 30$ centímetros de altura X 30 centímetros de largura) tem um espaço interior apropriado para que uma pessoa introduza a cabeça e a "use". E depois que "veste" o "Caruana das Imagens", a pessoa adquire a forma de um boneco humano "carnavalizado", já que a câmera-caixa possui como adereços diversas fitas coloridas a sua volta, sendo muito similar à estrutura do "Boi-Bumbá" ou "Bumbameu-Boi", em que o "Tripa" movimenta o Boi, com o revoar das fitas amarradas em seu chifre, pelo que o "Caruana das Imagens" já nasce agregado às diversas encenações tradicionais que envolvem as culturas populares amazônidas.

Ao "vestirem" a "Caruana das Imagens", revezando-se, crianças e jovens dão vida ao objeto, assumindo o corpo da câmera. E o "Caruana" se torna em uma câmera animada, cujos movimentos dependem de quem a "usa". É, pois, um exercício metodológico em forma de brincadeira. Este jogo permite que os participantes vivenciem uma lúdica experiência sensorial que é única. Desenvolve a prática do cinema a partir dos próprios olhos. Se os olhos são a janela da alma, quem usa o "Caruana" vê as imagens com os olhos da câmera, ao mesmo tempo em que filma com os próprios olhos.

Além da consciência ecológica, que potencializa a filosofia da reciclagem criativa, desde a procura da caixa no lixo, a limpeza, a escolha dos materiais e adereços, até a confecção da câmera, o "Caruana das Imagens" desperta a visão e a representação 
para a própria câmera, sendo os participantes do jogo-metodológico convocados a narrar o que "filmaram", quando assumiram a "representação" da câmera. É um momento em que a narrativa e a imaginação assumem um valor inestimável, como se a fala e a escuta de cada uma das pessoas do coletivo ocupasse um lugar sagrado. Neste momento, aprofunda-se a técnica e a percepção, o significado de movimentos e enquadramentos, do mesmo modo, a composição, as cenas, e até mesmo o "trabalho" dos atores. Não há limites para uma criação libertária. Mas, o grande segredo - ou a magia - deste processo é que na parte frontal exterior do "Caruana" há um pequeno espaço, onde é introduzida uma microcâmera de filmar (pode ser um telefone celular), que fica ligada e que capta os movimentos e ações de quem "veste" e dos demais participantes que "representam" para o "Caruana". E o resultado - com a projeção real das imagens - é uma agradável e alegre surpresa para todos, com os participantes a se auto reconhecer e a estabelecer relações de afeto e de identidades com as imagens que eles próprios construíram, captaram, e nelas e para ela se (auto) re-(a)presentaram. E estas diversas imagens captadas pelo coletivo - de forma lúdica - empoderam ainda mais os participantes das oficinas de Cinema de Guerrilha. Consequência direta desta práxis metodológica, mas que por ser "inconsciente", ela se processa de acordo com o tempo de cada um, é que alguns se tornam mais ativos, reconhecendo-se como responsáveis pelo próprio estado de arte e de criação, pelo que abandonam a condição de "objetos", para se "empoderar" da qualidade de sujeitos das imagens que desejam produzir. E produzem.

\section{CONCLUSÃO}

Tão invisível quanto o Cinema de Guerrilha, quase na mesma condição de "apagamento", somos um tipo de pesquisador que faz análises sob a perspectiva científica, mas que as destrói sob a ontológica metafisica artística. Escrevemos, refletimos, agimos, pesquisamos imagens que ninguém viu, fazemos filmes que talvez nem sejam vistos, pelo que nem estranhamos quando pensamos "cinema" e "memória" (na Amazônia) em "tempo" de esquecimentos, nestes processos civilizatórios que apagam ciclos históricos, onde rastos se tornam poeiras, cósmicas, e renascem míticos, mas não mediáticos.
As imagens dos filmes que criamos e projetamos não são reais, mas urgem à realidade, de tão reveladoras de realidades, ao mesmo tempo em que as resignificam para um estágio catatônico, numa espécie de insônia, em que não se pode adormecer, apenas sonhar. $E$ ainda que nasçam num espaço real, estas imagens vão além dos olhares, enquanto paisagens visuais perpetuadas por uma tradição que não se fixa ao "tempo", espraia-se à vida cotidiana por entre as relações que as gentes estabelecem entre si e com as culturas que produzem nestes lugares ignorados.

Imagens, entre memória e imaginário, suspensas por paradigmas monolíticos destruídos pela velocidade da sabedoria popular, reveladas num permanente ensimesmar, em que as pessoas se veem (a si próprias) e se identificam não mais como imagens projetadas, mas com (seus) projetos, e com (seus) sonhos nos quais o cinema é arma ao serviço dos excluídos.

\section{NOTAS}

01. Disponível em https://www.youtube.com/ watch?v=4PbE_NFCJ7Q

02. Alguns destes paradigmas serão abaixo especificados.

03. "Estéticas de Guerrilhas" é um conceito em construção, originário das forças propulsoras de manifestações poéticas e cinematográficas de comunidades periféricas e quilombolas da Amazônia Paraense.

04. Raymundo Heraldo Maués esclarece que os "encantados", são "pessoas que, ao contrário dos santos, não morreram, mas se encantaram". ("Um aspecto da diversidade cultural do caboclo amazônico: a religião").

05. O termo "Caruana" remete aos encantados da Amazônia Paraense. Ao falar da "grande riqueza de mitos, concepções, crenças e práticas" míticas da Região do Salgado, Raymundo Heraldo Maués esclarece que os caruanas são considerados "bichos do fundo", a partir de influências de "concepções de origem indígena", e "também por concepções de entidades de origem africana, como os orixás, seres que não se confundem com os espíritos 
dos mortos" ("Um aspecto da diversidade cultural do caboclo amazônico: a religião").

06. Esta "díade" será mais adiante desdobrada.

07. A Associação de Desenvolvimento Sustentável das Comunidades Quilombolas Terra Liberdade reúne 8 comunidades dos municípios de Cametá e Mocajuba, em algumas das quais desenvolvemos oficinas de Cinema de Guerrilha.

08. Projeto de Desenvolvimento Solidário e Sustentável da Comunidade do Mola/Cametá (PA): Identidade - Direitos - Qualidade de Vida.

09. Médico, Antropólogo, professor e coordenador do Programa Doutoral em Bioantropologia da Amazônia pela Universidade Federal do Pará.

10. O conceito de rizoma está no "centro" da teoria das multiplicidades de Deleuze \& Guattari (Mil Platôs - capitalismo e esquizofrenia), da qual nos apropriamos para "justificar" a ruptura das Estéticas de Guerrilhas com o "ideal" de vanguarda. eurocêntrica, assim como com as teorias cinematográficas do entretenimento "disponibilizadas" pela Indústria Cultural, que submete o público à passiva e castradora condição de espectador.

11. Carapajó é um afluente do Tocantins que também dá nome a uma Vila que tem importância na Região pesquisada.

12. Disponíveis em https://www.youtube.com/ watch?v=Rm6qRchd10U

13. Passada de geração em geração, esta antiga tradição consiste numa dança cujo ritmo é produzido pela batida de dois "cacetes" de madeira na lateral de um tambor oco, feito de um único tronco roliço, também de madeira, com uma das extremidades coberta por peles de animais silvestres.

14. Historiador e Mestre em Ciências da Religião.

15. Todos estes filmes estão disponíveis no Canal do pesquisador, playlist "Cametá", em https:// www.youtube.com/playlist list $=$ PL 8hqo6 Lh PuP2gZFt7FIMy6mdEnNy4IOiW

16. Artista Plástico, Mestre de Cultura Popular, parceiro do pesquisador em diversos projetos artísticos e cinematográficos.

\section{REFERÊNCIAS BIBLIOGRÁFICAS}

ALVES, Jaquicilene Ferreira da Silva. Educação quilombola, cinema e práticas educativas em direitos humanos: as identidades das crianças em Gurugi e Ipiranga-PB. Dissertação (Mestrado), Programa de Pós-Graduação em Formação de Professores, da Universidade Estadual da Paraíba, 2019.

ACEVEDO, Rosa Elizabeth Acevedo; \& CASTRO, Edna Maria Ramos de. Mobilização política de comunidades negras rurais. Domínio de um conhecimento praxiológico. Novos Cadernos NAEA, vol. 2, n 2 - Dezembro 1999 P. 73-106 Disponível em < http://dx.doi.org/10.5801/ncn. v2i2.110> Acesso em 12 Jun 2020.

BAUMAN, Zygmunt. Entrevista. Revista ISTO É. Disponível em <https://istoe.com.br/102755_VIVE MOS+TEMPOS+LIQUIDOS+ NADA+E+PARA+DURAR +> Acesso em 12 Jun 2020.

CHAGAS, Tamara. Situação T/T1, de Artur Barrio, e a arte-guerrilha conforme Frederico Morais. ARTis ON, n. 5 (Janeiro), 2018, p. 134-42. Disponível em <http://artison.letras.ulisboa.pt/index.php/ao/ article/view/138> Acesso em 12 Jun 2020

DEBORD, Guy. A sociedade do espetáculo e outros textos (1967). Livros da Revolta. Disponível em <http://www.afoiceeomartelo. com.br/posfsa/autores/Debord,\%20Guy/A\%20 Sociedade $\% 20$ do $\% 20$ Espetaculo $\% 20-\% 20$ Guy\%20Debord.pdf>Acesso em 12 Jun 2020.

DELEUZE, Gilles \& GUATTARI, Felix. Mil Platôs capitalismo e esquizofrenia, vol 1. Trad Aurélio Guerra Neto e Célia Pinto Costa - Rio de Janeiro. Ed 34, 1995. Disponível em < http://escolanomade. org/wp-content/downloads/deleuze-guattarimil-platos-vol1.pdf> Acesso em 12 Jun 2020.

FREITAS, Artur. Contra-Arte: vanguarda, conceitualismo e arte de guerrilha - 1969-1973. Tese (Doutorado), Programa de Pós-Graduação em História do Setor de Ciências Humanas, Letras e Artes. Universidade Federal do Paraná. Curitiba, Paraná, 2007. Disponível em <https:// acervodigital.ufpr.br/handle/1884/27151> Acesso em 12 Jun 2020.

GONÇALVES, Fernando do Nascimento. Poéticas políticas, políticas poéticas: comunicação e 
sociabilidade nos coletivos artísticos brasileiros. In:

Revista da Associação Nacional dos Programas dePós-Graduaçãoem Comunicação|E-compós, Brasília, v.13, n.1, jan./abr. 2010. Disponível em <https://www.academia.edu/8204370/ Po\%C3\%A9ticas_pol\%C3\%ADticas_ pol\%C3\%ADticas_po\%C3\%A9ticas_ comunica\%C3\%A7\%C3\%A30_e_sociabilidade_ nos_coletivos_art\%C3\%ADsticos_brasileiros $>$ Acesso em 12 Jun 2020.

MAUÉS, Raymundo Heraldo. Um aspecto da diversidade cultural do caboclo amazônico: a religião. In VIEIRA, Célia Guimarães et al. (orgs.). Diversidade biológica da Amazônia. Belém, Museu Paraense Emílio Goeldi, 2001, pp. 253-272 Disponível <em http://www.revistas.usp.br/eav/ article/view/10058> Acesso em 12 Jun 2020.

OLALQUIAGA, Felipe. Arte de Guerrilha: práticas contemporâneas. Trabalho de Conclusão de Curso. Centro de Estudos Latino-Americanos sobre cultura e comunicação. São Paulo, 2019. Disponível em <http://celacc.eca.usp.br/sites/ default/files/media/tcc/felipe_ramon_alves_ olalquiaga.pdf > Acesso em 12 Jun 2020.

POJO, Eliana Campos. Gapuiar de saberes e de processos educativos e identitários na comunidade do Rio Baixo Itacuruçá, Abaetetuba-PA. Tese (Doutorado), Programa de Pós-Graduação em Ciências Sociais do Instituto de Filosofia e Ciências Humanas da Universidade Estadual de Campinas, Unicamp, 2017. Disponível em <http://repositorio.unicamp.br/jspui/handle/ REPOSIP/330844> Acesso em 12 Jun 2020

RIBEIRO, José da Silva. Antropologia visual, práticas antigas e novas perspectivas de investigação. Rev. Antropol.vol.48 no.2São Paulo July/Dec. 2005. Disponível em <http://dx.doi. org/10.1590/S0034-77012005000200007> Acesso em 12 Jun 2020.

SALLeS, Vicente. O Negro no Pará. Fundação Getúlio Vargas / Universidade Federal do Pará. Rio de Janeiro, GB, 1971. Disponível em <https://ufpadoispontozero.wordpress. com/2013/03/15/o-negro-no-para $>$ Acesso em 12 Jun 2020.

\section{SOBRE O AUTOR}

Francisco Weyl é doutorando em Artes Plásticas (Faculdade de Belas Artes - Universidade do Porto), Mestre em Artes e Pós-graduado em Semiótica (Universidade Federal do Pará, Brasil), Bacharel em Cinema (Escola Superior Artística do Porto). Poeta, realizador, cineclubista, jornalista, radialista, professor, ensaísta, artivista digital. 